\title{
EL CANTO: EL DIOS PROFUNDO DE PABLO DE ROKHA
}

\author{
The singing: The deep God of Pablo de Rokha
}

Asunción Rangel López*

\section{RESUMEN}

La poética del chileno Pablo de Rokha tiene como vértice el canto. La exploración poética que de esta idea hace el autor de Los gemidos inicia en Versos de infancia (1916) y a traviesa toda su obra hasta Los borrachos dionisiacos (1966). El artículo intenta mostrar de qué manera, para el poeta chileno, el canto es sinónimo de vida y de poesía. El canto, pese a las apreciaciones de la crítica en torno a la obra de Pablo de Rokha, es transparencia de la vida y confirmación de la misma. Este rasgo de la poética derrokhiana, devuelve a la poesía a una de sus funciones antiquísimas y primordiales: cantar. Así, el canto es para este poeta su dios profundo, a quien dirige sus plegarias y lamentaciones, pero también a quien maldice y culpa de su trágica existencia. Palabras clave: Poesía chilena, poética, canto, vitalidad.

\begin{abstract}
Chanting is the axe of Chilean poet Pablo de Rokha's poetics. The poetic exploration of this idea vy the autor of Los gemidos, begins whit Versos de infancia (1916) and develops through his entire oeuvre up to Los borrachos dionisiacos (1966). The article intends tos hoy how chanting is a synonym of life and poetry for the Chilean poet. Despite the interpretations concerning Pablo de Rokha's work, chanting mean both transparency and confirmation of life. This derrokhian poetics characteristic returno to poetry one of its primary and former functions: chanting. Thus, this poet's inner god is chanting, the one he addresses hi sprays and laments to, but also the one he curses and blames for his tragic existence.
\end{abstract}

Key Words: Chilean poetry, poetry, chanting, vitality.

* $\quad$ Universidad de Guanajuato, Departamento de Letras Hispánicas, México.

Correo electrónico: asuncionrangellopez@gmail.com

Recepción: 14/1/2014 Aceptación: 23/2/2014. 
Yo canto, canto sin querer, necesariamente, irremediablemente, fatalmente, el azar de los sucesos, como quien come, bebe o anda y porque sí; moriría si NO cantase, moriría si NO cantase; el acontecimiento floreal del poema estimula mis nervios sonantes, no puedo hablar, entono, pienso en canciones, no puedo hablar, no puedo hablar; las ruidosas, trascendentales epopeyas me definen, e ignoro el sentido de mi flauta; aprendí a cantar siendo nebulosa, odio, odio las utilitarias, labores, zafias, cuotidianas, prosaicas, y amo la ociosidad ilustre de lo bello; cantar, cantar, cantar... -he ahí lo único que sabes, Pablo de Rokha!... (De Rokha, 1994: 23²)

Con estas líneas abre el poemario Los gemidos (1922), uno de los primeros libros publicados por Carlos Ignacio Díaz Loyola, nombre verdadero del chileno. Desde 1922, se convierte, con éste, su que se juega la vida misma, mantendrá su tenor y talante hasta la última de las páginas escritas o garabateadas por el originario de Licantén, una comuna central de Chile, fundada primero como una estancia colonial, y que hasta 1864 alcanza el estatuto de aldea gracias a la fundación de una parroquia y al consecuente incremento de casas alrededor de la iglesia.

El talante de la fatalidad y el gemido surgen en 1922 con la publicación del mencionado poemario, y ambos rasgos se mantendrán, como ha quedado señalado, hasta los poemarios publicados -aún mientras de Rokha vivía- en la década de 1960. El clamor, el gimoteo derrokhiano -que dista mucho del caos del alarido, como se verá más adelantees una suerte de pilastra o de columna en la que se sostiene cada una de las obras de este poeta chileno, de tal manera que ese gimoteo, tratado de diversas formas, tematizado, poetizado y traducido de diferentes maneras, atraviesa y sostiene su propuesta poética. En otras palabras: el clamor permanece en la poesía de Pablo de Rokha.

El gemido es, en la poética de Pablo de Rokha, un canto sin querer, esto es, algo que se da por excedente y que está profundamente vinculado a la fatalidad, pero también con su contracara: la vitalidad. El canto, que desde sus primeros versos es clamor, es comida, bebida, es andar; esto es: lo justo y necesario para vivir, para la vida, ni poco más, ni poco menos. La pérdida de alguno de estos elementos tendrá como consecuencia la muerte. Pero se trata de la muerte del canto que, en Pablo de Rokha, es la poesía. Sin canto no hay vida: "como quien come, bebe o anda y porque sí; moriría si NO cantase, moriría si NO cantase", dice el también autor de Escritura de Raimundo Contreras (1929).

Ahora bien, el gemido le viene de dentro, de su interioridad; y no podría ser de otra manera. Tal como despunta en las primeras líneas de Los gemidos, es algo necesario, irremediable, fatal y azaroso, pero además es algo que "estimula mis nervios sonantes". El canto viene de esa condición sine qua non fatal y azarosa -como la vida misma- y toma forma, o se expresa, en el poema. Así, el poema regresa a la interioridad del poeta para estimular sus "nervios sonantes". Esto permite percibir la dimensión absolutamente sonora que reverbera en las nervaduras de la poética derrokhiana. La confirmación de esa interioridad, en detrimento de lo exterior, lo cual, en este momento de la obra de Pablo de Rokha adquiere la forma del habla, o más bien, de una imposibilidad por hablar y en la absoluta posibilidad de entonar, de pensar en canciones: "no puedo hablar, entono, pienso en canciones", dice el poeta chileno. Las descripciones o, diría más bien, las imágenes poéticas que vienen a continuación, versan sobre dos asuntos capitales en la tarea de comprender o atisbar qué es el gemido en la poética derrokhiana. Primero, los asuntos sobre los que el poeta tiene certeza: el saberse definido por "las ruidosas, trascendentales epopeyas", el saber que aprendió a cantar "siendo nebulosa", el saber que ama "la ociosidad ilustre de lo bello, y que lo único que sabe es "cantar, cantar, cantar". Segundo, la absoluta ignorancia del "sentido de mi flauta".

Esta declaración de principios poéticos, condensada en las primeras líneas de su libro de 1922, encierra, en mi opinión, una clave desde la que se puede leer toda la obra de Pablo de Rokha, ya que ella contiene uno de los muchos de los temas que le preocuparán y sobre los que escribirá durante toda su trayectoria; y para lo 
que me interesa señalar aquí: la tensa y no fácil relación entre el interior y el exterior.

\section{En el principio, el gemido}

"Los Gemidos, madurado entre 1916 y 1922, es un libro de ruptura no sólo con la poesía anterior, sino también con la poesía del momento. En Chile, con la excepción de Huidobro, la poesía seguía una tradición romántica-modernista. En este ambiente, el libro provocó extrañeza, asombro e indiferencia" (8), apunta Naín Nómez en el prólogo a Los gemidos que la editorial LOM imprimió con motivo del centenario del nacimiento del poeta. Las críticas que reproduce el especialista en la poesía de Rokha, confirman esa "extrañeza, asombro e indiferencia". Por ejemplo, en la revista Claridad de 1922, afirma Cesar Bunster:

Pablo de Rokha colecciona expresiones sucias, de pura cepa chilena, que luego da a la publicidad en sus artículos y libros... y así vemos que en de Rokha todo es difuso y extendido, ya que una idea mínima nada en una página como modesto díptero urbano en una taza de leche. Y así, todo en su técnica se disimula gelatina verbal (en Nómez: 9)

Años más tarde la propia crítica literaria se encargaría de restituir el lugar y la importancia de ese libro de Rokha en el contexto de la vanguardia poética. Me interesa destacar aquí esa extrañeza, esa "suciedad", lo "difuso y extendido", la "gelatina verbal". En el caso de Naín Nómez, la adjetivación poco tiene qué ver con lo peyorativo, no así en el caso de Bunster, para quien, a todas luces, la escritura derrokhiana poco tiene de poética o de "acertada".

La escritura de Pablo de Rokha, por supuesto, resultaría sucia y gelatinosa, difusa. Al crítico de la revista Claridad, me atrevo a aventurar, le parecería "extraña" la manera en que el poeta chileno se pronunció poéticamente sobre los asuntos dignos de su atención. Y no era para menos. Siguiendo las apreciaciones de Nómez, en el contexto de la estética románticomodernista, los textos que dan forma a Los gemidos poco tienen qué ver con las creencias poéticas de los mencionados movimientos. Me parece que es Pablo Neruda -uno de los enemigos poéticos favoritos de Pablo de Rokha- quien describe con mayor precisión esa "extrañeza", esa estridencia o chirrido que le son propias a Los gemidos:

Un impulso hacia la raíz transcendente del hecho,
una mirada que escarba y agujerea en el esqueleto de
la vida y un lenguaje de humano, de hijo de mujer, un
lenguaje exacerbado, casi siempre sabio, de hombre
que grita, que gime, que aúlla, ésa es la superficie de
Los gemidos. Más adentro, libres ya de las palabras,
de los alaridos y de las blasfemias, sentimos un
amador de la vida y de las vidas, azotado por la furia
del tiempo, por los límites de las cosas, corroído
hasta la médula por la voluntad de querer y por la
terrible tristeza de conocer (en Nómez: 10).

Neruda distingue dos niveles: el de la superficie, donde prevalecen el grito, el gemido, el aullido; y el profundo, donde gobiernan el alarido y la blasfemia. Sin embargo, en Los gemidos, me parece, todas estas maneras de expresión del hombre, del poeta, encuentran cobijo en el canto. Ese canto extraño, esos ruidos del mundo cotidiano -el crujir de un mueble, el gemido que asemeja o evoca una voz humana-son para Pablo de Rokha los materiales primigenios de su poesía, de su verso.

Ecuación, Canto de la fórmula estética (1929), Canto de hoy (1932), Canto de trinchera (1933), Cinco cantos rojos (1938), Canto al ejército rojo (1944), son algunos de los títulos de las obras que en vida publica De Rokha. Es evidente, como echa de verse en los mencionados títulos, la propensión o la predilección del poeta chileno por la forma "canto", y no podría ser de otra manera. La acuciosa y profunda lectura que hizo los clásicos griego y latinos (Lucrecio, Plauto, Heráclito, Zenón, Demócrito y Virgilio) dejó una fuerte impronta en su manera de pensar y la poesía. Acudir a esta forma fija de la tradición literaria -el canto-, incluso en el pleno auge de la vanguardia, da muestra de ello ${ }^{2}$. Como es de esperarse, el cultivo del canto, la escritura del mismo, reverbera en la obra de Pablo de Rokha pero, por supuesto, no al estilo griego o latino, sino revitalizada, revivificada y 
llevaba a otras latitudes, a otras manifestaciones escriturales. Lo que conserva el canto de la épica, de los cantos épicos, es la visión de la vida, esto es: trágica. Y no sólo eso, además, los embates del sujeto frente a las pasiones comunes o sublimes, el desgarramiento que produce su enfrentamiento con la vida misma. A diferencia de los grandes poemas épicos (piénsese por ejemplo en la Odisea, el Cantar del mío Cid), el sujeto poético derrokhiano difícilmente alcanza la victoria final.

De Rokha recupera este antiquísimo tópico literario -el sentimiento trágico de la vida, para usar las palabras de Miguel de Unamuno- de manera casi obsesiva. Si bien se puede advertir a primera vista en los títulos de sus poemarios, también en los contenidos de sus obras es palpable que sus sujetos poemáticos están constantemente embebidos de tragicidad. Ahora bien, no sólo por eso escribe en este, por así decir, registro trágico. Le interesa, como he dicho párrafos arriba, la capacidad de cantar, incluso en las condiciones amargas y adversas en que se inscribe el héroe trágico.

El gemido, el clamor, la queja o el grito son algunas de las formas que toma el canto en la poesía de Pablo de Rokha. No se trata de un simple lloriqueo o lamentación. Todo lo contrario: es el gemido o el grito primordial, aquello que de primera intención intenta comunicar algo, decir algo, significar algo. Ésta es la manera en que Pablo de Rokha intenta hablar en un lenguaje poético primigenio, original: encontrar la palabra fundacional, aquella que dio vida a todo, al nombrarlo todo por primera vez.

Para Naín Nómez la huella que De Rokha deja en la literatura chilena, acaso la escrita en español, es absolutamente enfática, "con ese énfasis que supo darle a toda su obra y su vida" (2003: 22). Vida y obra son inseparables. Sus cuantiosos viajes, su ríspida relación con Pablo Neruda y Vicente Huidobro, su áspero vínculo con el Partido Comunista, y cómo vuelca estos asuntos en sus poemas, no dejan lugar a dudas. Sin embargo, la vinculación de la vida con la obra va más allá de los paralelismos entre el día a día y la escritura de sus versos.
El autor de Escritura de Raimundo Contreras sabía, como lo sabían escritores de la talla de Franz Kafka o Rainer Maria Rilke, que el canto de la poesía despliega la vida, con las vicisitudes y amargos desencantos, con lo dolorosa y agónica que ésta es. De ahí que la tragicidad y el canto aparezcan desde sus primeros textos, porque ahí nace o germina la vida de estos asuntos que discutirá, ensayará, experimentará e intentará a lo largo de toda su escritura. A Pablo de Rokha no le interesa culminar o agotar ese tema, sino el movimiento hacia él, la aproximación que lo hace posible, porque en esa tarea que nace en sus Versos de infancia (1916) y que vive y agoniza hasta Los borrachos dionisiacos (1966), brota y se arraiga, con fuerza propia, el deseo de seguir escribiendo, de seguir cantando. Se trata de una suerte de eterna reiteración, de inaugurar un canto que, sabe, no cesará jamás porque eso que íntima, personal y vitalmente le fascina y obsesiona volverá a brotar en otros libros, en otros poemas.

Así como las líneas que abren el poemario Los gemidos ponen de manifiesto la pulsión por el canto, en "Genio y figura" de Versos de infancia:

Yo soy como el fracaso total del mundo, ;oh Pueblos!

El canto frente a frente al mismo Satanás,

dialoga con la ciencia tremenda de los muertos,

y mi dolor chorrea de sangre la ciudad (2003: 25).

Tres afirmaciones despuntan en el cuarteto: yo soy, el canto dialoga y mi dolor chorrea. Respecto de los potenciales sentidos que genera el canto desafiado a Satán, y particularmente por las resonancias que este otro tópico establece entre la obra derrokhiana, me ocuparé más adelante. En este momento quiero resaltar esta inicial inclinación y predilección por la fuerza del canto; de tal raigambre es su potestad que De Rokha lo afronta a Satanás; de tal envergadura, que sólo 
el canto es capaz de dialogar "con la ciencia tremenda de los muertos".

En Ecuación (canto de la fórmula estética) (1929), y a manera de sentencias o aforismos, vuelve a despuntar la alta consideración que el poeta chileno le tiene al canto:

2

Que nunca el canto se parezca a nada, ni a un hombre, ni a un alma, ni a un canto.

$[\ldots]$

4

¿Qué canta el canto? Nada. El canto canta, el canto canta, no como el pájaro, sino como el canto del pájaro.

$[\ldots]$

19

El canto, como el mundo (2003: 127-128).

De manera análoga, como en el cuarteto citado de Versos de infancia, en estos aforismos descuella la afirmación del canto por encima de absolutamente todo. El canto es la vida. Esto permite sostener que, pese a las certeras apreciaciones de la crítica -sobre lo hiperbólica, caótica y chirriante de la escritura derrokhiana-, si algo hay en claro en la poética del chileno es la transparencia de la vida, una confirmación de la misma.

Para De Rokha el canto -más bien, la capacidad de cantar- antecede a la forma "poema". De ahí que la forma que toma su escritura sea tan diversa: a veces sonetos, a veces aforismos, a veces elegía o prosa poética. Para el autor de Los gemidos el canto es, y nada más. La tarea del poeta, una vez que comprende y asume esta creencia, consiste en vaciar en la escritura su canto. Como es de suponerse, en el auge de las vanguardias, la destrucción o discrepancia con las formas poéticas, no era novedad. Lo que convierte a Pablo de Rokha en un poeta genuino es, en mi opinión, este voto de creencia poética en algo fundacional para la poesía.

El canto es para De Rokha su dios profundo, a quien eleva plegarias y lamentaciones, pero también al que maldice e impreca; un dios que lo hace chirriar y gemir. No en vano, en diversos momentos de su obra, se resiste a nombrarlo cabalmente. Lo que se encuentra en la lectura de su poesía es un procedimiento a través del cual alcanza, acaso, a decir algo acerca de él. Así queda de manifiesto en los aforismos arriba citados. Por ejemplo: "El canto, como el mundo".

\section{Un solitario literario, un rijoso poético}

Antes, me he referido a las "creencias poéticas" de Pablo de Rokha. El entrecomillado supone una dificultad, más aún si se trata de la obra de un escritor que dedicó buena parte de sus escritos a dilucidar, discutir y reflexionar sobre qué es la poesía y la naturaleza de la relación entre la interioridad del poeta y el mundo exterior. La creencia implica una suerte de fe ciega, por así decir, en ciertos preceptos, y en De Rokha si no hay lugar para algo es precisamente para la fe, para la creencia ciega e incondicional en algo. Habría que decir, en este sentido, "pensamiento poético", ya que se trata de una fina y detenida reflexión sobre los temas aludidos. Este pensamiento emerge con fuerza y solidez propia no sólo en los “ensayos" que De Rokha dedicó, por ejemplo, a la estética. Los escritores de vanguardia, como es sabido, ponían de manifiesto sus preceptos literarios en sendos manifiestos. De Rokha, si bien perteneció al grupo denominado runrunista $^{3}$, nunca se adscribió a cabalidad a algún movimiento de vanguardia chileno. Pablo de Rokha era un solitario literario, un rijoso poético, y para muestra, las disputas que entabló con Neruda y Huidobro.

Pablo de Rokha, como Kafka, Mallarmé o Lautréamont, es un autor para el cual no era posible confundir vida y literatura, porque simplemente eran la misma cosa. La poesía está en la vida misma, parece decirnos todo el tiempo en sus versos. Y la vida es, ni qué decir, dulzura y zozobra, pero también un fruto amargo que hay que morder. Los sinsabores y agonías que despuntan en su biografía, lo hacen también en sus versos. Nunca disoció militancia 
e ideología; nunca disoció el desgarro que le supuso la muerte de sus hijos. Resulta elocuente, por ejemplo, Escritura de Raimundo Contereras, escrito en memoria de Tomás de Rokha.

Al referirme al "pensamiento literario" en la obra del chileno, intento aludir, primero, a una actitud vertical que atraviesa lo biográfico, pero además, a una idea de escritura literaria que no guarda distingos entre verso o prosa, entre disertación política y reflexión literaria, entre poema y aforismo. Para De Rokha, así como literatura y vida son lo mismo, también lo son poema y aforismo o ensayo; la forma discursiva que su pensar y su sentir encuentren no tiene importancia. Los significativo, lo valioso, radica en que en el principio de su obra germina una preocupación que irá proliferándose y extendiéndose a lo largo de todos sus libros. Y en el centro de esa preocupación está el canto, como un dios.

De Rokha, como lo hicieron muchos escritores incluso antes de la vanguardia, genera en sus escritos no un pensamiento de la literatura, sino un pensamiento en la literatura ${ }^{4}$. Este tipo de pensamiento, hay de resaltar, genera una especie de conocimiento que poco tiene que ver con el conocimiento en el terreno de la ciencia. Se trata -como lo muestra ejemplarmente Ramón Xirau en "Poesía y conocimiento", especialmente sobre la noción de imaginación en Coleridge-, de un conocer que identifica creación, imaginación y conocimiento. La imaginación secundaria -que es donde opera la poesía- primero "«disuelve» y «disipa», y en una segunda etapa definitiva, verdaderamente crea" (Xirau, 1993: 17). Ahora bien, pensar en la literatura y hacer de esto un principio, tiene como derivación suscribir un "género literario llamado literatura que todo lo incluye, que no tiene límites y que está hecho de contradicciones. Una consecuencia de todo ello es que los recursos expresivos del lenguaje literario como, por ejemplo, la tropología, el fragmentarismo, [...] van a estar presentes en el momento en que la literatura se ponga a hablar de sí misma" (Asensi, 2003: 349).

Si De Rokha leyó o no a los románticos alemanes, es un asunto que aquí no voy a corroborar o discutir. Lo que me interesa destacar son los momentos en que las reflexiones sobre la literatura en su escritura asoman y se ponen de manifiesto, algunas veces a través del fragmento o del aforismo, y otras más en sus propios versos. Además, la idea del canto como el tema del que no deja de escribir, al que vuelve rabiosamente en su poesía, acerca la obra de este chileno a algunas de las líneas de pensamiento acerca de la infinitud, de lo inacabado o de propensión por lo que siempre está por venir. Lo infinito es un asunto, huelga decir, que ocupa buena parte del pensamiento de Friedrich Nietzsche, filósofo al que Pablo de Rokha frecuentó con asiduidad. La impronta del filósofo de la vitalidad, asoma en Sátira de 1918:
El mundo se transforma, trabaja, piensa y ríe
en la máquina actual, infinita y divina,
en la ciudad moderna, que es trágica y no es triste,
en el ilimitado Zaratustra de Nietzsche
y no en vuestros minúsculos gritos de sabandijas (2003: 29).

Hay que mencionar, al respecto, el título de uno sus libros en donde es manifiesta la resonancia del pensamiento nietzscheano: Los borrachos dionisiacos $\left(1966^{5}\right)$.

El séptimo fragmento del libro Ecuación (canto de la fórmula estética), reúne una serie de consideraciones que muestran el estatuto privilegiado que ocupa el canto en el pensamiento derrokhiano, así como también la propensión por la infinitud, por lo que está siempre por venir, y además ahí se vuelca esa concepción de Pablo de Rokha acerca de que vida y poesía son la misma cosa:

\footnotetext{
Si un volumen, únicamente, un volumen agranda o empequeñece la astronomía del poema, incendiad el poema, no el volumen, degollad el poema porque no aguantó el desorden necesario a la colosal aritmética de lo pitagórico, lo geométrico, lo matemático, lo filosófico -en el teorema expresivo-inexpresable-; ¿sobre la forma?, ¿una forma?, ¿una ley?, ¿una voz?, ¿una luz?, ¿un régimen o un vértice?, ¿un ritmo índice adentro de la libertad numérica del arte?, incendiad el poema, degollad el poema; el porvenir del canto, su destino innumerable y único, exige que giren todos
} 


\begin{abstract}
los elementos épicos alrededor de su eje astronómico, amarrándose a esa justicia, a esa presencia, a esa cordura que es el poema, el provenir del canto, su destino innumerable y único, exige que giren todos los elementos épicos alrededor de su eje astronómico, amarrándose a esa justicia, a esa presencia, a esa cordura que devine lo absoluto, límite del límite, arte, lo exacto, lo exactísimo, arte, lo dinámico-trágico e inmóvil (2003: 126).
\end{abstract}

El precepto es claro: incendiar y degollar la forma poema. Frente al potencial agradecimiento y empequeñecimiento de la astronomía del poema, el llamado derrokhiano apunta a velar por el volumen. En la tercera línea del fragmento, acaso se alcanza a distinguir un parangón entre volumen y desorden, rasgos fundamentales del poema que deben soportar los embates de la "aritmética de lo pitagórico, lo geométrico, lo matemático, lo filosófico". Se trata de una embestida brutal entre lo aparentemente racional, inmóvil e inagotable que no olvida $-\mathrm{O}$ recuerda, más bien- su profundo lazo con lo pasajero, lo temporal, lo contradictorio, lo inútil y efímero, esto es: la propensión, la preferencia derrokhiana por ubicarse en la dolorosa y compleja relación entre lo inacabable y lo finito. Así lo deja ver, también, la dupla "expresivoinexpresable" que antecede a las preguntas que el propio De Rokha intenta resolver en la segunda parte del fragmento arriba citado.

El poeta interpela a "lo pitagórico, lo geométrico, lo matemático, lo filosófico" a través de las preguntas "¿sobre la forma?, ¿una forma?, ¿una ley?, ¿una voz?, ¿una luz?, ¿un régimen o un vértice?" en aras, me parece, de encontrar el "teorema expresivo-inexpresable"; se trata de una tesis que dé cabida y haga posible conjuntar los opuestos. La respuesta, si acaso la encuentra, está cifrada en el volumen, que es aquello que el poeta debe proteger celosamente.

No es gratuita, como todo en poesía, la mención a "lo pitagórico". Con el ánimo de indicar la pulsión derrokhiana por contraponer opuestos, me permito apuntar, muy someramente, algunos rasgos del pensamiento pitagórico. De acuerdo con Giovanni Reale y Dario Antiseri:

[...] el pitagorismo primitivo se planteó la antítesis originaria entre ilimitado y limitador en un sentido cosmológico. Lo ilimitado es el vacío que rodea al todo y el mundo nace mediante una especie de «inspiración» de dicho vacío por parte del Uno (cuya génesis no se especifica en exactitud). El vacío que entra con la inspiración, y la determinación que provoca el Uno al inspirarlo, dan origen a las diversas cosas y a los distintos números (1988: 50).

La mención a "lo pitagórico" en el texto de Pablo de Rokha despliega ciertos sentidos si tenemos presente esta idea pitagórica sobre el origen de las cosas. Al autor de Los gemidos le interesa discernir, por lo menos en el fragmento que he citado arriba, si una forma, una ley, una luz, un régimen o un vértice, serían aquellas categorías que le sirvan para resolver la tensión expresable-inexpresable. Sobre todo porque discute si es una forma, una ley o un régimen, una luz, alguna de aquellas coordenadas, por así decir, aquello que servirían al poeta para volcar en la poesía lo que desea decir, cantar. Como se nota, no es así del todo.

De Rokha ni deshecha ni anula el orden numérico o racional de su horizonte poético, todo lo contrario; sabe que el poeta debe padecer ese embate bestial, y que, en todo caso, privaría un "índice adentro de la libertad numérica".

Cierto que en la obra derrokhiana impera el desorden, el caos, el alarido, lo desarticulado. Pero bien visto, ese caos no olvida -o recuerda, más bien- su natural contracara: el orden, la claridad y el método. Lo significativo en el caso de Pablo de Rokha es, justamente, que logra conciliar entre ambos polos. Al estado de desconcierto, llega siempre el de la serenidad y la calma; a la turbación, el sosiego:

[...] incendiad el poema, degollad el poema; el porvenir del canto, su destino innumerable y único, exige que giren todos los elementos épicos alrededor de su eje astronómico, amarrándose a esa justicia, a esa presencia, a esa cordura que es el poema, el provenir del canto, su destino innumerable y único, exige que giren todos los elementos épicos alrededor de su eje astronómico, amarrándose a esa justicia, a esa presencia, a esa cordura que devine lo absoluto, límite del límite, arte, lo exacto, lo exactísimo, arte, lo dinámicotrágico e inmóvil (126).

Incendiar y degollar el poema, así, dista de una gana de la destrucción por la simple 
destrucción. El canto pervive siempre con un pie puesto en lo contrario: un eje, la justicia, la cordura. Se alcanzan a advertir, en esta segunda parte del fragmento, dos zonas más o menos definidas. Por una parte, lo pitagórico, lo aritmético y geométrico, que alcanzan un parangón con lo justo, lo cuerdo, lo único de la primera parte. Por otro lado, el incendio, la degolladura, que se hermanan con lo innumerable y con una palabra clave en todo el fragmento: el porvenir. En lo que vendrá, lo que siempre está en ciernes, gestándose, es donde Pablo de Rokha encuentra conjunción entre lo dinámico y lo inmóvil; me parece que ésa es la naturaleza del volumen del que habla al inicio del séptimo fragmento de Ecuación (canto de la fórmula estética).

"Incendiad el poema, no el volumen", dicta De Rokha, porque el volumen implica la manera en que un cuerpo puede expresarse: largo, ancho y alto; porque el volumen todo lo contiene; en él, todo es susceptible de ser cualquier cosa. En y a partir del volumen emerge la idea de libertad. De ahí que a Pablo de Rokha no le satisfaga ninguna ley, ninguna forma, ninguna voz, sino precisamente lo que antecede la ley, la forma, la voz. Cuando el poema es forma, ley, voz, luz, un régimen, hay que incendiarlo, porque en ello se advierte que la tarea del poeta está terminada. Incendiarlo y degollarlo, siempre recelando el volumen, son acciones que prometen que el poema se convertirá en algo infinito, susceptible de ser escrito otra vez, otra vez y siempre.

Esto se traduce en, efectivamente, una pulsión en la poética derrokhiana, una pulsión que quiere decir deseo; deseo por la libertad y por la afirmación de la vida, de la poesía. Afirmar este deseo, en De Rokha, es acercarse de medio a medio, a su vena nietzscheana. Me atrevo a aventurar que mucha de la impronta vital en la poesía de Pablo de Rokha viene, precisamente, de la lectura del filósofo alemán.

En los siguientes párrafos, y últimos, de esta ruta de lectura de la poesía del chileno, intentaré indicar en qué zonas las ideas derrokhianas están emparentadas con algunos momentos del pensamiento nietzscheano, no con el ánimo de discutir y problematizar las ideas de este último, sino, insisto, con la intención de mostrar en qué momento y de qué manera ese vitalismo derrokhiano es de un profundo amor y admiración por la filosofía del alemán, y particularmente sobre dos asuntos: el canto y el mal.

El canto les fue dado a los hombres, el poeta es el ser que multiplica el valor del habla, a través de su canto. En él y sólo él, quien es capaz de loar las victorias de los héroes, o de cantar sus desdichas. Y fueron los griegos, ni más ni menos, quienes no lo enseñaron. Para Rubén Bonifaz Nuño, son estos algunos de los rasgos que definen el antiguo espíritu griego:

[...] el violento trabajo de la voluntad para regir la sedición de los instintos; la guerra sin término en busca del dominio sobre los otros hombres: el encontrar en ese dominio la suma de las virtudes, y utilizar los dictados de la ley y la religión para justificarlo; al mismo tiempo, seguir las aspiraciones de un idealismo ilimitado, y pretender hallar sus valores absolutos en lo más inmediato: oscilar entre la crueldad y si disimulación, y querer establecer la sabiduría sobre la agitación perpetua de perversas pasiones; cultivas con disciplina el físico esplendor como vía de la humana perfección (2005: IX).

Píndaro, como es sabido, es el poeta que cantó a estos atributos humanos. Y su canto estaba dirigido a asuntos lejanos al desenfreno y la orgía dionisíaca, tópicos que sirvieron a Nietzsche para hablar de la existencia trágica. Así y todo, lo que me interesa resaltar es cómo en el principio está el canto. Dionisio y las bacanales, el espíritu de ambos, sirvieron al filósofo alemán para referirse a experiencias vitales que, en intensidad, se desatan en el canto: el vino, la danza, la música y el instinto liberado; "bajo el arrebato de lo dionisíaco, no solamente se sella de nuevo la alianza entre hombre y hombre; también la alienada, hostil y sojuzgada naturaleza celebra otra vez su fiesta de reconciliación con su hijo pródigo que es el hombre", y unas líneas más adelante: "Entonces aparecen de repente y desenfrenadas las otras fuerzas simbólicas [a contra pelo con lo apolíneo]: las de la música, con su ritmo, dinamismo y armonía" (en Hernández-Pacheco, 1990: 32-33). 
Se trata, como ha quedado señalado, del privilegio y profundo amor que De Rokha le profesa a esa fuerza primaria y primordial: el canto que siempre está gestándose, germinando, creciendo y muriendo. Frente a la idea de finito, de acabado, contra la que el pensamiento nietzscheano va una y otra vez, se encuentra la pulsión por lo infinito.

\section{No el bien, sino el mal, sobre todo el mal}

Tener hambre es una bendición si hay, a la mano, un pedazo de pan. En caso contrario, el hambre se convierte en un mal, en algo que no se puede satisfacer ${ }^{6}$. Ese mal, en el que se ha convertido el hambre es para el hambriento la única realidad del mundo, lo único que hay. De haber un pedazo de pan a la mano, el mordisco, la satisfacción pasajera del hambre, convierte a ese mal en un momento de plenitud y de placer.

El canto en Pablo de Rokha es una loa, una alabanza a, precisamente, esa idea del mal. En Imprecación a Satanás:

Creo en Dios, como el espanto inicial del conocimiento, la mentira animal prolongándose inmensa y dolorosamente hacia la eternidad balbuciente de las últimas, pálidas, pálidas, últimas e inútiles experiencias, el espectro monumental, crepuscular o absurdo del binamo que emerge, emerge, emerge, agobiado con el misterio azul de los anchos asombros elementales hasta las montañas de la amargura racional [...] (1922: 59).

La filiación nietzscheana es indudable. En la siguiente parte de este fragmento de Imprecación a Satanás:

[...] he mirado pasar, TRANQUILAMENTE, al poeta de ayer por el camino, sin crepúsculos, de la belleza habitual, inmóvil con la inmovilidad del concepto e ingenuamente feliz, ingenuamente feliz, ingenuamente feliz, pero tu canto horrible de maldito, alarido de fúnebres, extraordinarios e inhábiles tonos ácidos, mortuorios, arrojó a la sombra de mis sesos ardientes la semilla hostil, la semilla hostil, embrión de plantas lúgubres, impudentes, tentaculares, envenenadas cual culebras, el horror, la tragedia que corroe y alumbra, alumbra colmado de canciones agrias, mi verdad superior, Satanás (59-60).
La creencia en un Dios "agobiado" encuentra su opuesto en la "verdad superior, Satanás". Contra lo pálido, lo absurdo, lo agobiante y la amargura racional se embiste "tu canto horrible de maldito", y este ese cantar, diametralmente opuesto a la apolínea serenidad, al orden y mesura, da pie -y no podría ser de otra manera- al alarido, a los tonos ácidos y mortuorios, el horror y la tragedia que, paradójicamente, alumbra como una canción agria esa "verdad superior". Nuevamente, estamos frente a la conjunción, a lo que está a medio camino entre el día y la noche, entre la mesura y el desenfreno. Lo significativo en De Rokha radica, precisamente, en que en su poética logra conciliar entre esos opuestos que, huelga insistir, son una suerte de unísono.

\section{Notas}

1. En las citas a la obra del chileno, se respeta la puntuación y sintaxis del poeta.

2. Habría que mencionar el Canto general, de Pablo Neruda, que se publica por vez primera hacia 1950, una vez que el periodo vanguardista, en estricto sentido, había culminado.

3. La fundación de la revista Dinamo, hacia 1924, llamó la atención de Vicente Huidobro. El autor de Altazor escribió una carta en el periódico $L a$ Nación, el 11 de junio de 1925, donde reconoce la impronta futurista de la publicación. A partir de este momento, Pablo de Rokha parece inscribirse en el programa estético del runrunismo que consiste, grosso modo, en: “a) hacer una caricatura fina, que se conseguiría con los recursos tradicionales; b) la búsqueda poética debería partir de los motivos corrientes; c) Chile sería la única fuente de inspiración y ambientación, se trataría de descubrir dentro del país el paisaje y las gentes como tema o núcleo de sus obras; d) se hacía un alarde de la renovación de estilo. No obstante, aunque los runrunistas aspiran a la originalidad, la perspectiva más amplia que da el tiempo ha demostrado que consciente o inconscientemente el runrunismo coincide con muchos de los afanes de otros ismos de vanguardia, los remeda o no pasa de ser un esfuerzo mimético. Esto se ve 
tanto en el sentido del nombre que se escoge a la vez: zumbido o sonido continuado, ronroneo; bramadera o especie de juguete o matraca [...]" (Videla en Ferreiro, 2006: 79).

4. Me refiero, particularmente, a los románticos alemanes de Iena que publicaron sus reflexiones en la revista Atheneum. Al respecto, indica Manuel Asensi: "Como señalaron en su día Ph. LacoueLabarthe y Jean Louc-Nancy, el proyecto romántico inaugurado por ese grupo de escritores no consistió en una teoría de la literatura, sino una teoría en la literatura. La diferencia entre la "de" y la "en" es aquí capital. [...] La diferencia entre la teoría de la literatura y la teoría en la literatura no tiene nada que ver con una mayor o menor seriedad o rigor, con un mayor o menor sentido del juego, sino con una presuposición epistemológica muy distinta: los autores que practican una teoría en la literatura están apasionadamente convencidos de que la literatura es un lenguaje omnicomprensivo, mucho más potente que los lenguajes científicos y, por ello mismo, absolutamente inabordable desde un supuesto exterior" (1998: 348-349). Pablo de Rokha, efectivamente, atraviesa por una etapa romántica, y esto ha sido señalado por algunos de los críticos de su obra. Me interesa, sin embargo, detenerme en este otro aspecto, en el "pensamiento en la literatura" que puede advertirse en la obra del poeta chileno. Pensar en la literatura es parangón de lo que he venido llamando "pensamiento literario".

5. Volveré más adelante a las resonancias de la filosofía vitalista de Nietzsche en el pensamiento literario derrokhiano.

6. La distinción entre querer y poder, en el pensamiento nietzscheano y como es sabido, resulta de gran importancia. Al respecto, remito a uno de los muchos estudios que proliferan sobre el filósofo alemán, Friedrich Nietzsche. Estudio sobre vida y trascendencia (1990), de Javier Hernández-Pacheco.

\section{Bibliografía}

Asensi Pérez, Manuel. (2003). Historia de la teoría de la literatura, volumen II. Valencia: Tirant lo Blanch.

Bonifaz Nuño, Rubén. (2005). "Introducción", en Píndaro. Odas: Olímpicas, Píticas, Nemeas, Ístmicas. Colección Bibliotheca Scriptorvm graecorvm et Romanorvm Mexicana. México: UNAM.

De Rokha, Pablo. (1922). Los gemidos. Santiago de Chile: LOM.

. (2003). Canto del macho anciano y otros poemas. Edición e introducción de Naín Nomez. Madrid: Biblioteca Nueva.

- (2008). Escritura de Raimundo Contreras. Santiago de Chile: Universidad Diego Portales.

Ferreiro González, Carlos. (2006). "La prosa narrativa de vanguardia en Chile", tesis doctoral. España: Universidad de Coruña.

Hernández-Pacheco, Javier. (1990). Friedrich Nietzsche, estudio sobre vida $y$ trascendencia. Biblioteca de Filosofía. Barcelona: Herder.

Reale, Giovanni y Dario Antiseri. (1988). Historia del pensamiento filosófico y cientifico. Antigüedad y Edad Media. Trad. Juan Andrés Inglesias. Barcelona: Herder.

Xirau, Ramón. (1993). Poesía y conocimiento. Dos poetas y lo sagrado. México: El Colegio Nacional.

\section{@) $\mathbb{\otimes} \Theta \Theta$}

Este obra está bajo una licencia de Creative Commons

Reconocimiento-NoComercial-SinObraDerivada 4.0 Internacional. 